\title{
METHODOLOGY OF FOOD DESIGN. PART 2. DIGITAL NUTRITIOLOGY IN PERSONAL FOOD
}

Keywords: digital nutrition, personalized nutrition, atherosclerosis, bioinformatics, nutritional genetics, FoodTech, preclinical trials

\begin{abstract}
Atherosclerosis (the main cause of a wide range of cardiovascular diseases) and other multifactorial diseases depend on several nutrition factors, defined in general by lifestyle that directly and constantly affects the human body. The modern level of science and technology development is able to form a diet, taking into account all personal characteristics in such a way that makes nutrition an effective preventive measure against diseases in order to keep a person healthy. The purpose of this article is to define and study all the limitations (the scope of its coverage in the scientific literature) that arose in the process of research aimed to formation of an integrated personal approach to designing of nutrition to prevent atherosclerosis. The object of the study was scientific literature, which is available in open source and free access databases: PubMed, ScienceDirect, eLIBRARY.RU, www.fips.ru, Patentscope. The language of search is Russian and English, search depth is 12 years. In the course of the research two food design concepts were found that affect process of digitalization in the food sector: the concept "FoodTech" (food technology) and digital nutritiology. It was established that in Russia only one company - LLC "City Supermarket" (Moscow), that works with the brand "Azbuka Vkusa" - acts in the sphere of "FoodTech" on the Russian market. This company selects personalized food, taking into account the results of personal nutrigenetic tests, in cooperation with LLC "Genotech" (Moscow). There is a need to use biological information, statistical information processing (nutrigenetic studies, nutrigenomic research) and machine-aided data processing (machine learning) for further generation of automatic algorithm that compiles personal recommendations. The relevance of generation of a national domestic database on chemical composition of food products (presented in the market) to simplify the preparation of individual personal diets is observed. We underline the necessity to use the test-organisms, i. e. dorio fish / zebrafish (Danio rerio) and nematodes (Caenorhabditis elegans)), which were used to determine the activity of candidate substances - the biologically active substances that feature antiatherosclerotic properties. In the future the authors plan to conduct a nutrigenomic and nutrigenetic study, using digital achievements. To collect information about consumers, it is necessary to apply digital devices, and use biological informatics to process the results; after that it is necessary to generate the algorithm for automatic selection of personalized dietary recommendations.
\end{abstract}

For citation: Prosekov, A.Y., Vesnina, A.D., Kozlova, O.V. (2021). The methodology of food design. Part 2. Digital nutritiology in personal food. Theory and practice of meat processing, 6(4), 328-334. https://doi.org/10.21323/2414-438X-2021-6-4-328-334

\section{Funding:}

The research was carried by a grant from the President of the Russian Federation with state support from leading scientific schools (№ 2694.2020.4).

\section{Introduction}

The development of " $4 \mathrm{P}$ " concept (product, place, price, promotion) in healthcare and the modern level of "omics" technologies led to the emergence of personalized nutrition [1]. The relevance of this idea is ensured by the fact that nutrition is an environmental factor that directly and constantly affects the consumer's health. Regulation of nutrition is capable to change the state of health of the body [2]. Personal nutrition takes into account the entirety of the individual consumer's characteristics, helps prevent the development of a range of chronic diseases, and therefore it features prophylactic function $[3,4]$. The general goal of the authors' research is to form an integrated approach to nutrition, including the selection of personal dietary recommendations and the development of individual functional food products (FFP) and biologically active additives (BAA) to prevent diseases [5-7]. In particular, for the prevention of atherosclerosis, as the root cause of a number of cardiovascular diseases, which occupy a leading position in the structure of human mortality throughout the world [8]. To achieve this goal, in their previous works the authors [9-11] emphasize the importance of a personal approach to nutrition to prevent development of chronic, multifactorial diseases, and draw their attention to:

- identified genes whose mutations affect nutrient metabolism and are associated with a predisposition to the development of a number of socially important diseases;

- identified genes influencing the development of atherosclerosis and associated with nutrition;

- presented an algorithm for developing a personalized diet;

- highlighted the strengths and weaknesses of personal nutrition. 
In the course of the study, a number of limitations arose that hindered the formation of an integrated approach to personal nutrition. For example, to form personal dietary recommendations, it is necessary to process a huge amount of information about the consumer: history data, family diseases, nutritional characteristics (intolerance, dependence, preference), body composition data (anthropometry, etc.) and nutrigenetic tests data [12]. Therefore, it is necessary to turn to the field of mathematical and bioinformatic data processing, etc. It's possible also to use modern gadgets to collect the necessary data. In the course of the research it became clear that is necessary to consider digitalization in personal nutrition planning.

The purpose of this work was to study and work out the limitations that arose during the study; in particular, during the study of the role of digital nutritionology in the modern concept of personalized nutrition. The research was conducted by analyzing scientific literature on this issue.

\section{Objects and methods}

The object of the research was scientific literature (articles, patented inventions), that covers the role of the digital approach in science of nutrition. The scientific literature was analyzed in the following databases: PubMed (United States National Library of Medicine), ScienceDirect, Scopus (Elsevier publishing house), eLIBRARY.RU electronic library, www.fips.ru search systems (Federal Institute of Industrial Property), Patentscope (World Intellectual Property Organization). The search covered the literature in English and Russian. The depth of search was 12 years.

\section{Results and discussion}

Digitalization is the introduction of modern digital systems and technologies into various spheres of human life [13]. In the course of a literature analysis, it was found that digital technologies are used in nutrition in "FoodTech" sphere, and in the field of nutrition directly.

"FoodTech" (Food technology) is a new branch of nutrition science associated with the new innovative tech- nologies, namely biotechnology, information and digital technologies. This is an aggregate set of operations and activities, starting from growing of raw materials, processing, food production, packaging, storage till the moment of sale and disposal of waste [14]. Consequently this industry branch is subdivided into two components:

1. Orientation towards the end consumer (B2C), towards the production of traditional food products, towards personalized nutrition.

2. Orientation towards businesses (B2B).

The world market of FoodTech consists of five areas of activity: development of technologies for obtaining alternative sources of protein (insects, algae, microorganismsprotein producers) $[15,16]$ and innovative food products (lactose-free, gluten-free food products, food with a low sugar content, etc.) [17], table 1; development and application of biotechnology in the field of agriculture (application of synbiotic additives for normalizing the digestive system of livestock, producing strains, strains for plants growth stimulation, etc.) [18]; application of digital technologies in the field of agriculture (application of machineaided data processing algorithms, automation, introduction of unmanned technologies, etc.) $[19,20]$; development of "smart packaging" (environmentally friendly and sustainable packaging, packaging that displays shelf life of the food products, etc.); development of personalized nutrition (nutrigenetic testing, study of the microbiota of the gastrointestinal tract, individual FFP) [14]. FoodTech provides for not production of food only, but also for their delivery (from catering businesses, shops) [21], which is in a great demand now due to the spread of coronavirus infection [22,23].

The Russian market for innovative products is mainly represented by functional drinks and food additives produced from alternative sources of nutrients by the companies located in the European part of the country. There is only one competitor on the market today that selects personalized food products based on genetic tests results. This information proves that it is possible to enter the market

Table 1. The example of a number of domestic companies engaged in innovative nutrition in FoodTech sphere

\begin{tabular}{|c|c|c|c|}
\hline Category & Food product & Producer, city & reference \\
\hline \multirow{3}{*}{ Innovative food products } & “NEORON” drink & LLC “SINCOR”, Moscow & {$[24]$} \\
\hline & “Octa” milk drink & LLC “Dairy Naro-Fominsk Plant”, Moscow & [25] \\
\hline & Chlorella drink "Be. Live.Organic" & LLC “Holdingvest”, Tver & {$[26]$} \\
\hline \multirow{4}{*}{ Nutritional supplements } & Fine powders & LLC “EVOFOOD”, Perm & [27] \\
\hline & Wolffia-based food additive "BIOVOLF" & LLC “BIOVOLF RUS”, Moscow & {$[28]$} \\
\hline & Sweetening proteins "Hi-Protein" & JSC “EFKO”, Alekseevka & {$[29]$} \\
\hline & Vegetable salt replacement & LLC “SALICORNIA NUTRITION”, Astrakhan & [30] \\
\hline Alternative protein source & Protein product from sunflower kernel "SFP-60" & LLC “ECO PRODUCT”, Moscow & {$[31]$} \\
\hline \multirow{2}{*}{ Alternative meat products } & Herbal food products "Greenwise" & CJSC “PARTNER-M”, Maloyaroslavetz & [32] \\
\hline & Vegetable meat "Hi!" & JSC “EFKO”, Alekseevka & {$[29]$} \\
\hline Personal food & $\begin{array}{l}\text { Range of food products from the private supermarkets } \\
\text { chain "Azbuka Vkusa" ("Alphabet of Taste") based on } \\
\text { nutrigenetic tests conducted by the company "Genotech" }\end{array}$ & LLC “City Supermarket”, Moscow & [33] \\
\hline
\end{tabular}


with individually selected dietary supplements and produced FFP. However this process is quite costly, which is explained by various difficulties in the field of food personalization. It is important that some of these difficulties (i. e. restrictions) will be eliminated by the introduction of digitalization in nutrition and preclinical researches.

The term "digital nutritiology" was presented for the first time in the Russian scientific literature in the paper of Yu. N. Orlov and his colleagues [34]. The paper developed an automatic algorithm for calculating the size of helping (food portion), taking into account the data on the daily intake of essential nutrients. There are three blocks that enable software implementation in the field of nutritional science:

- the first block - an aggregate set of models of food digestion by a body, that is taking into account all body's basic features (gender, age, weight, level of physical activity, etc.) and data on the health of the consumer, as well as his / her cultural and religious preferences;

- the second block - an aggregate set of data on chemical composition of food product (before and after its cooking by various cooking methods);

- the third block - an aggregate set of computational algorithms compiled for analysis of information from the first two blocks. Those algorithms select the composition and size of helping based on individual data about the consumer, and are able to evaluate the menus made according to consumer preferences, etc.

The role of digitalization in this case is that the collection and aggregation of information on the consumer (i. e. the first block) is possible thanks to modern gadgets used in real time mode (cell phones with special applications, wearable technologies devices - smart watches, etc.) [3538]. On the modern market there is a huge variety of mobile applications that assist in weight management, control the therapeutic diets and give advice for people with diabetes, gastrointestinal tract issues, allergic reactions to certain food components, etc. $[39,40]$. To calculate the algorithms that define helping sizes and so on, statistical and bioinformatic data processing is required. Traditional elements of statistical analysis of nutritional data include: $t$ tests, analysis of variance (ANOVA), analysis of covariance (ANCOVA) [41,42], chi-square, regression [43], etc. These operations play an important role in describing nutritional information; they are able to transform the received data into analytical variables. But they cannot interpret the large amount of data collected during the formation of personal dietary recommendations, when analyzing the relation between intake of nutrients and the health of a consumer. Therefore it is necessary to supplement traditional statistical methods with machine-aided processing of data[44,45]. Machine-aided processing of datarefers to a computer system capable of describing the solution to a given problem and creating an algorithm based on this solution. More details about machine-aided processing of datamethods are presented in the work of L. Khorramine- zhad, [46]. You also need to use programs like Python (Python), R, RStudio, Statistics, etc. to process the collected data.

For the formation of an individual diet for the prevention of both atherosclerosis and any other disease, it is important to create a domestic database on the chemical composition of food products. The demand for this database is caused by the fact that its availability will simplify the development of personal dietary recommendations by specialists and individual dietary supplements, food additives and FFPs for prevention of diseases. This topic is considered in more detail in the paper of $\mathrm{V}$. V. Bessonov and his colleagues [47]. For a detailed study of the chemical composition of food products, it is necessary to improve the methods used in the "Foodomics" approach. This approach is the discipline of studying food, using "omics" technologies (that is genomics, transcriptomics, proteomics and metabolomics) to improve the quality of food, functional food activity and assessment of the food safety [48]. Due to necessity to process a large amount of information this area is also closely related to bioinformatics [49]. Methods of analytical chemistry play a significant role in Foodomics technologies, namely chromatographic analysis, mass spectrometry, nuclear magnetic resonance, as well as methods of sample preparation, extraction and purification of biologically active substances (BAS) from the researched raw materials [50], methods of genetic analysis to detect food pathogens [51].

In order to organize an experiment in silico, the initial data from experiments in vivo and / or in vitro are required. So an important problem is to assess the efficiency of the developed FFP and dietary supplements assigned to prevent atherosclerosis. During the review of the scientific literature it was noted that it was possible to evaluate on model test systems the following parameters in in vitro conditions:

1. The ability of cell lines to accumulate cholesterol. Cellular models are presented in the work of A. N. Orekhova and his colleagues [52]. Thus, to assess the anti-atherosclerotic potential of the studied biologically active substance, it is necessary to cultivate human aortic cells under conditions of gradual adding atherogenic serum / atherogenic serum plus biologically active substances.

2. The ability to transform foam cells on human monocytes (THP-1). Monocytes were transferred into macrophages, then into foam cells (using oxidized lipoprotein of low density) in the presence / absence of the studied BAS. The technique is described in the paper of X. W. He [53].

3. The ability of probiotics, synbiotics to change the level of cholesterol in the nutrient medium. The technique is thoroughly described in the work of D.K Lee [54].

To assess the efficiency of dietary supplements / food additives and FFP in vitro, Figure 1 below is compiled to show all test models being researched in comparison with the model of a human [55]. 


\begin{tabular}{|c|c|c|c|c|c|c|c|}
\hline & PARAMETERS & शृ: Nema- & $\begin{array}{r}\text { Droso- } \\
\text { phila }\end{array}$ & $\begin{array}{ll}\equiv & \text { Zebra- } \\
\equiv & \text { fish }\end{array}$ & thy Frogs & Mice & 赵 Human \\
\hline \multirow{5}{*}{$\frac{n}{\frac{2}{4}}$} & Fat tissue & $\overline{-1}$ & Thick body & 4 & 5 & 5 & 4 \\
\hline & Liver & 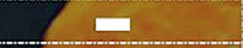 & Thick body & 4 & 4 & 4 & 5 \\
\hline & Pancreas & & $\begin{array}{l}\text { Insulin } \\
\text { producing } \\
\text { cells }\end{array}$ & 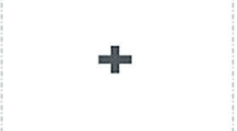 & 4 & 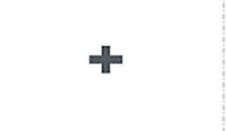 & + \\
\hline & Placenta & 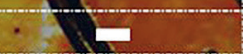 & $=$ & ש & $=$ & $\Rightarrow$ & $\Rightarrow$ \\
\hline & Lacteal gland & 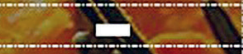 & $=$ & $=$ & $=$ & 4 & 4 \\
\hline \multirow{3}{*}{$\frac{5}{\frac{5}{2}}$} & $\begin{array}{l}\text { Venue } \\
\text { of the } \\
\text { experiment }\end{array}$ & Any vess & Flasks & Water vessels & Water vessels & $\begin{array}{c}\text { Supervised } \\
\text { cages } \\
\text { (1-4 mice } \\
\text { per cage) }\end{array}$ & $\begin{array}{l}\text { Variable, } \\
\text { controlled }\end{array}$ \\
\hline & Nutritive substrate & $\begin{array}{l}\text { Growth } \\
\text { medium }\end{array}$ & Wet powder & $\begin{array}{l}\text { Pellets / flakes } \\
\text { (added } \\
\text { to water) }\end{array}$ & $\begin{array}{l}\text { Pellets } \\
\text { (added } \\
\text { to water) }\end{array}$ & $\begin{array}{l}\text { Dry powder } \\
\text { or granules }\end{array}$ & Variable \\
\hline & Keeping costs & Low & Low & Moderate & Moderate & Very high & Very high \\
\hline \multirow{2}{*}{$\frac{8}{4}$} & $\begin{array}{l}\text { Interval } \\
\text { of generations }\end{array}$ & 4 days & 1 week & Months & Months & Months & Decades \\
\hline & $\begin{array}{l}\text { Number } \\
\text { of offsprings } \\
\text { in the brood }\end{array}$ & Hundreds & Hundreds & Hundreds & Hundreds & $<12$ & $1-2$ \\
\hline
\end{tabular}

Figure 1. Model test organisms suitable for Nutrigenetic Research

The genetic information of all the test organisms, shown in the figure above, has been decoded. That made them suitable for research in the field of nutritional genetics. But zebrafish (Danio rerio) and nematodes (Caenorhabditis elegans) were of particular interest as they feature genetic similarity to the human genome, they feature rapid development, high fertility; they are easy to conduct genetic manipulation on, as well as the costs of their keeping are relatively low, as well as fewer ethical limitations in comparison with models of mammals and large amphibians [56]. In the scientific literature, zebrafish are the model organisms of scientific priority in studies related to nutritional genetics and development of obesity [57]. The zebrafish can also be used for researches related to cardiovascular diseases and metabolic syndrome $[58,59]$. Due to the fact that nematodes (Caenorhabditis elegans) have a transparent body, they can be used to study the accumulation of lipids - their body accumulates fats in the form of droplets in the subcutaneous and intestinal cells, which are clearly visible to the observer [60]. Nematodes are also used for research targeted to finding candidate genes related with human obesity [61]. Consequently, these test models can be used for further research targeted at finding the relation between nutritional genetics and development of atherosclerosis.

\section{Conclusion}

Nowadays the personalization in the healthcare system is an urgent preventive system; in particular, the personalization is expressed in a way of individual nutrition. This article briefly summarizes the authors' findings within the research conducted in the nutritional genetics, and represents the revealed limitations. Limitations are related to digitalization in the nutrition system and preclinical studies, which serve as a source of data for further machineaided processing of data, for statistical forecasting, etc. In this paper it was found that:

- all "omics" technologies are aimed at prevention of diseases development and ensuring the normal well-being of the consumer;

- processing of data obtained via "omics" technologies is not possible without the introduction of digital technologies;

- the role of digitalization in the modern world keeps growing, and its achievements can be used to develop personalized nutrition;

- in the sphere of nutrition, digitalization is implemented in the form of "FoodTech" and in nutritional science directly;

- development of algorithms for the automatic selection of appropriate food, according not only to its composition and size of helping, but also for drawing of dietary recommendations for the prevention of diseases (in particular atherosclerosis) is of high relevance now; - in order to develop these algorithms, it is necessary to involve data on basic characteristics of consumers. Some of that data can be collected via mobile applications, smart watches and other digital devices;

- in order to develop there algorithms, it is necessary to involve data on chemical composition of food products and its biologically active features;

- in order to study the chemical composition and safety of existing food products and developed FFP, dietary supplements, it is necessary to develop Foodomics technology; 
- to assess the efficiency of the selected nutrition, FFP and dietary supplements, it is necessary to conduct preclinical studies on the model test systems;

- nematodes (Caenorhabditis elegans) and zebrafish (Danio rerio) are the promising test organisms;

- the researches on cell models in vitro are of relevance too;

- bioinformatics methods are necessary to process the obtained data of "omics" (nutrigenomic and nutrigenetic research) analysis;

- on the domestic market there is a service for selection of personal food products, taking into account the results of nutrigenetic testing. This service is provided by only one company, that is LLC "City Supermarket" (that operates under the brand "Azbuka Vkusa") in cooperation with LLC "Genotek".

Within the course of further research the authors plan to form personal dietary recommendations, aimed at the prevention of atherosclerosis, on the basis of nutrigenetic tests; also to make a list of BAS-candidates which feature anti-atherosclerotic properties; to run preclinical tests i. e. nutrigenomic research; to evaluate the efficiency of the selected biologically active substances on the model systems in vitro, in vivo. The authors plan to conduct research in silico, on the basis of the collected data; further to form an integrated approach to nutrition to prevent atherosclerosis, as well as to develop individual dietary supplements and FFP.

\section{REFERENCES}

1. Di Renzo, L., Gualtieri, P., Romano, L., Marrone, G., Noce, A., Pujia, A. et al. (2019). Role of personalized nutrition in chronic-degenerative diseases. Nutrients, 11(8), Article 1707. https://doi. org/10.3390/nu11081707

2. Smetneva, N. S., Pogozheva, A. V., Vasil'ev, Y. L., Dydykin, S. S., Dydykina, I. S., Kovalenko, A. A. (2020). The role of optimal nutrition in the prevention of cardiovascular diseases. Voprosy Pitaniia, 89(3), 114-124. https://doi.org/10.24411/0042-88332020-10035 (In Russian)

3. Horne, J. R., Nielsen, D. E., Madill, J., Robitaille, J., Vohl, M. -C., Mutch, D. M. (2021). Guiding global best practice in personalized nutrition based on genetics: The development of a nutrigenomics care map. Journal of the Academy of Nutrition and Dietetics, https://doi.org/10.1016/j.jand.2021.02.008 (unpublished data)

4. Blue, T. (2019). Charting the course to success in the era of personalized nutrition. (2019). Integrative medicine (Encinitas), 18(1), 34-37.

5. Vlasschaert, C., Goss, C. J., Pilkey, N. G., McKeown, S., Holden, R. M. (2020). Vitamin k supplementation for the prevention of cardiovascular disease: Where is the evidence? a systematic review of controlled trials. Nutrients, 12(10), 1-25, Article 2909. https://doi.org/10.3390/nu12102909

6. Cullen, A. E., Centner, A. M., Deitado, R., Fernandez, J., Salazar, G. (2020). The impact of dietary supplementation of whole foods and polyphenols on atherosclerosis. Nutrients, 12(7), 1-36, Article 2069. https://doi.org/10.3390/nu12072069

7. Penson, P. E., Banach, M. (2021). Nutraceuticals for the control of dyslipidaemias in clinical practice. Nutrients, 13(9), Article 2957. https://doi.org/10.3390/nu13092957

8. Wei, T., Liu, J., Zhang, D., Wang, X., Li, G., Ma, R. et al. (2021). The relationship between nutrition and atherosclerosis. Frontiers in Bioengineering and Biotechnology, 9, Article 635504. https://doi.org/10.3389/fbioe.2021.635504

9. Prosekov A. Yu. (2020). The methodology of food design. Part 1. The individual aspect. Theory and Practice of Meat Processing; 5(4), 13-17. https://doi.org/10.21323/2414438X-2020-5-4-13-17

10. Vesnina, A., Prosekov, A., Kozlova, O., Atuchin, V. (2020). Genes and eating preferences, their roles in personalized nutrition. Genes, 11(4), Article 357. https://doi.org/10.3390/ genes11040357

11. Vesnina, A.D. (2021). Formation of personalized dietary recommendations for the prevention of atherosclerosis. Food Systems, 4(3S), 37-41. https://doi.org/10.21323/2618-97712021-4-3S-37-41 (In Russian)

12. Rollo, M. E., Haslam, R. L., Collins, C. E. (2020). Impact on dietary intake of two levels of technology-assisted personalized nutrition: A randomized trial. Nutrients, 12(11), 1-15, Article 3334. https://doi.org/10.3390/nu12113334

13. Costa Climent, R., Haftor, D. M. (2021). Business model theory-based prediction of digital technology use: An empirical assessment. Technological Forecasting and Social Change, 173, Article 121174. https://doi.org/10.1016/j.techfore.2021.121174 14. Kanunnikova, K.I., Khvoynikov, A.N., Pavlova, E.A., Orlova, O. Yu. (2021). Prospects for the development of the FoodTech market in Russia. Russian Journal of Innovation Economics, 11(2), 523-536. https://doi.org/10.18334/vinec.11.2.112082 (In Russian)

15. Baurina, A. V., Baurin, D. V., Shakir, I. V., Panfilov, V. I. (2021). Technology for the bacillus megaterium fodder biomass production. Food Processing: Techniques and Technology, 51(1), 134145. https://doi.org/10.21603/2074-9414-2021-1-134-145 (In Russian)

16. Zhebo, A.V., Aleshkov, A.V., Kalenik, T.K. (2019). Technology and characteristics of plant-based milk substitutes. ESSUTM Bulletin, 4(75), 25-31. (In Russian)

17. Nikitina, J.V., Topnikova, E.V., Lepilkina, O.V., Kashnikva, O.G. (2021). Technological and methodological aspects of the production of low- and lactose-free dairy products. Food Systems, 4(2), 144-153. https://doi.org/10.21323/2618-9771-2020-4-2144-153 (In Russian)

18. Laptev G. Yu., Novikova N. I., Nikonov I. N., Melikidi V. Kh., Brazhnik E. A., Bikonya S. N. et al. Probiotic feed additive for farm animals, poultry, horses and fish. Patent RF, no. 2652836, 2018. (In Russian)

19. Fedorenko, V.F., Mishurov, N.P., Petukhov, D.A., Trubnikov, A.V., Semizorov, S.A. (2019). Precision farming technology: Differential fertilization considering the in-tra-field heterogeneity of the soil-ground cover. Machinery and Equipment for Rural Area, 2, 2-9. https://doi.org/10.33267/2072-9642-2019-2-2-7 (In Russian)

20. Shashko, A. Yu., Bandarenka, U. Yu., Charnysh, M. A., Przhevalskaya, D. A., Usnich, S. L., Pshybytko, N. L. et al. (2020). Modern phenotyping platforms and their application in plant biology and agriculture. Journal of the Belarusian State University. Biology, 2, 15-25. https://doi.org/10.33581/2521-1722-2020-215-25 (In Russian)

21. Chernikov, Ya. Yu. (2021). FoodTech - a modern vector in the development of the food industry. Vestnik Universiteta, 1, 120125. https://doi.org/10.26425/1816-4277-2021-1-120-125 (In Russian)

22. Tiunov, V.M. (2020). Foodtech and the digitalization of public catering in Russia. Modern Science and Innovation, 3(31), 17-21. https://doi.org/10.37493/2307-910X.2020.3.2

23. Karapetyan, R.V. (2019). Revolution of food 4.0 - new challenges to modern society. International Journal of Applied and Fundamental Research, 10, 230-234. https://doi.org/10.17513/ mjpfi.12899 (In Russian)

24. Non-carbonated soft drink, developed by the Federal Scientific Center for Food Systems of the Russian Academy of Sciences. (2019). Retrieved from http://neoron.ru. Accessed September 20, 2021. (In Russian)

25. Milk drink "Octa". (2019). Retrieved from https://octa-food. com/. Accessed September 20, 2021. (In Russian)

26. Chorella-based drink. (2016). Retrieved from https://beliveorganic.com/composition. Accessed September 20, 2021. (In Russian)

27. Fine powders from natural products. (2018). Retrieved from https://evofood.ru/. Accessed September 20, 2021. (In Russian) 28. Wolffia-based food additive "BIOVOLF". (2019). Retrieved from http://volfia.com/. Accessed September 20, 2021. (In Russian) 
29. "Hi" food products. (2018). Retrieved from: https://www. efko.ru/. Accessed September 20, 2021. (In Russian)

30. Plant salt substitution "Salicornia" (2018). Retrieved from http://www.greensalt.ru/. Accessed September 20, 2021. (In Russian)

31. Production and sale of sunflower protein for the food industry (2018). Retrieved from http://www.sunflower-protein.ru/. Accessed September 20, 2021. (In Russian)

32. Plant food products "Greenwise". (2019). Retrieved from https://greenwise.ru/. Аата обращения: 20.09.2021. (In Russian)

33. "Azbuka Vkusa" and the genetic center "Genotek" will select food products, basing on genetic predispositions. (2006). Retrieved from https://clck.ru/YzhXG Accessed September 20, 2021. (In Russian)

34. Orlov, Y. N., Kislitsyn, A. A., Kambarov, A. O., Baturin, A. K., Nikituk, D. B., Tutelian, V. A. (2020). Digital nutrition: Spectral portraits of optimal diet. Scientific Visualization, 12(2), 139-150. https://doi.org/10.26583/sv.12.2.11

35. Limketkai, B. N., Mauldin, K., Manitius, N., Jalilian, L., SaIonen, B. R. (2021). The age of artificial intelligence: Use of digital technology in clinical nutrition. Current Surgery Reports, 9(7), Article 20. https://doi.org/10.1007/s40137021-00297-3

36. Kelly, J. T., Collins, P. F., McCamley, J., Ball, L., Roberts, S., Campbell, K. L. (2021). Digital disruption of dietetics: Are we ready? Journal of Human Nutrition and Dietetics, 34(1), 134-146. https://doi.org/10.1111/jhn.12827

37. Tay, W., Kaur, B., Quek, R., Lim, J., Henry, C. J. (2020). Current developments in digital quantitative volume estimation for the optimisation of dietary assessment. Nutrients, 12(4), Article 1167. https://doi.org/10.3390/nu12041167

38. König, L.M., Attig, C., Franke, T., Renner, B. (2021). Barriers to and facilitators for using nutrition apps: Systematic review and conceptual framework. JMIR mHealth and uHealth, 9(6), Article e20037. https://doi.org/10.2196/20037

39. Fatehah, A. A., Poh, B. K., Shanita, S. N., Wong, J. E. (2018). Feasibility of reviewing digital food images for dietary assessment among nutrition professionals. Nutrients, 10(8), Article 984. https://doi.org/10.3390/nu10080984

40. Hu, E. A., Nguyen, V., Langheier, J., Shurney, D. (2020). Weight reduction through a digital nutrition and food purchasing platform among users with obesity: Longitudinal study. Journal of Medical Internet Research, 22(9), Article e19634. https://doi. org/10.2196/19634

41. Mishra, P., Singh, U., Pandey, C.M., Mishra, P., Pandey, G. (2019). Application of student's t-test, analysis of variance, and covariance. Annals of cardiac anaesthesia, 22(4), 407-411. https://doi.org/10.4103/aca.ACA_94_19

42. Ali, Z., Bhaskar, S. B. (2016). Basic statistical tools in research and data analysis. Indian Journal of Anaesthesia, 60(9), 662-669. https://doi.org/10.4103/0019-5049.190623

43. McHugh, M. L. (2012). The chi-square test of independence. Biochemia Medica, 23(2), 143-149. https://doi.org/10.11613/ bm.2013.018

44. De Silva, K., Lim, S., Mousa, A., Teede, H., Forbes, A., Demmer, R. T. et al. (2021). Nutritional markers of undiagnosed type 2 diabetes in adults: Findings of a machine-aided processing of dataanalysis with external validation and benchmarking. PLoS ONE, 16(5 May), Article e0250832. https://doi.org/10.1371/ journal.pone.0250832

45. Chin, E. L., Simmons, G., Bouzid, Y. Y., Kan, A., Burnett, D. J., Tagkopoulos, l. et al. (2019). Nutrient estimation from 24-hour food recalls using machine-aided processing of dataand database mapping: A case study with lactose. Nutrients, 11(12), Article 3045. https://doi.org/10.3390/nu11123045

46. Khorraminezhad, L., Leclercq, M., Droit, A., Bilodeau, J. -F., Rudkowska, I. (2020). Statistical and machine-learning analyses in nutritional genomics studies. Nutrients, 12(10), 1-19, Article 3140. https://doi.org/10.3390/nu12103140

47. Bessonov, V. V., Bogachuk, M. N., Bokov, D. O., Makarenko, M. A., Malinkin, A. D., Sokurenko, M. S. et al. (2020). Databases of the chemical composition of foods in the era of digital nutrition science. Voprosy Pitaniia, 89(4), 211-219. https://doi. org/10.24411/0042-8833-2020-10058 (In Russian)

48. Cifuentes, A. (2009). Food analysis and foodomics. Journal of Chromatography A, 1216(43), 7109. https://doi.org/10.1016/j. chroma.2009.09.018

49. Capozzi, F., Bordoni, A. (2013). Foodomics: A new comprehensive approach to food and nutrition. Genes and Nutrition, 8(1), 1-4. https://doi.org/10.1007/s12263-012-0310-x

50. Class, L. -C., Kuhnen, G., Rohn, S., Kuballa, J. (2021). Diving deep into the data: A review of deep learning approaches and potential applications in foodomics. Foods, 10(8), Article 1803. https://doi.org/10.3390/foods10081803

51. Andjelković, U., Gajdošik, M. S., Gašo-Sokač, D., Martinović, T., Josić, D. (2017). Foodomics and food Safety: Where we are. Food Technology and Biotechnology, 55(3), 290-307. https://doi. org $/ 10.17113 / \mathrm{ftb} .55 .03 .17 .5044$

52. Orekhov, A. N., Ivanova, E. A. (2016). Cellular models of atherosclerosis and their implication for testing natural substances with anti-atherosclerotic potential. Phytomedicine, 23(11), 1190-1197. https://doi.org/10.1016/j.phymed.2016.01.003 53. He, X. -W., Yu, D., Li, W. -L., Zheng, Z., Lv, C. -L., Li, C. et al. (2016). Anti-atherosclerotic potential of baicalin mediated by promoting cholesterol efflux from macrophages via the PPARY-LXR $\alpha$ ABCA1/ABCG1 pathway. Biomedicine and Pharmacotherapy, 83, 257-264. https://doi.org/10.1016/j.biopha.2016.06.046

54. Lee, D. K., Jang, S., Baek, E. H., Kim, M. J., Lee, K. S., Shin, H. S. et al. (2009). Lactic acid bacteria affect serum cholesterol levels, harmful fecal enzyme activity, and fecal water content. Lipids in Health and Disease, 8, Article 21. https://doi. org/10.1186/1476-511X-8-21

55. Chowanadisai, W., Hart, M. D., Strong, M. D., Graham, D. M., Rucker, R. B., Smith, B. J. et al. (2020). Genetic and genomic advances in developmental models: Applications for nutrition research. Advances in Nutrition, 11(4), 971-978. https://doi. org/10.1093/advances/nmaa022

56. Fowler, L. A., Williams, M. B., Dennis-Cornelius, L. N., Farmer, S., Barry, R. J., Powell, M. L. et al. (2019). Influence of commercial and laboratory diets on growth, body composition, and reproduction in the Zebrafish Danio Rerio. Zebrafish, 16(6), 508-521https://doi.org/10.1089/zeb.2019.1742

57. Landgraf, K., Schuster, S., Meusel, A., Garten, A., Riemer, T. Schleinitz, D.et al. (2017). Short-term overfeeding of zebrafish with normal or high-fat diet as a model for the development of metabolically healthy versus unhealthy obesity. BMC Physiology, 17(1), 1-10, Artilcle 4. https://doi.org/10.1186/s12899-0170031-x

58. Gut, P., Reischauer, S., Stainier, D. Y. R., Arnaout, R. (2017). Little fish, big data: Zebrafish as a model for cardiovascular and metabolic disease. Physiological Reviews, 97(3), 889-938. https://doi.org/10.1152/physrev.00038.2016

59. Benchoula, K., Khatib, A., Jaffar, A., Ahmed, Q. U., Sulaiman, W. M. A. W., Wahab, R. A. at al. (2019). The promise of zebrafish as a model of metabolic syndrome. Experimental Animals, 68(4), 407-416. https://doi.org/10.1538/expanim.18-0168

60. Bouyanfif, A., Jayarathne, S., Koboziev, I., \& Moustaid-Moussa, $N$. (2019). The nematode caenorhabditis elegans as a model organism to study metabolic effects of $\omega-3$ polyunsaturated fatty acids in obesity. Advances in Nutrition, 10(1), 165-178. https://doi.org/10.1093/advances/nmy059

61. Ke, W., Reed, J. N., Yang, C., Higgason, N., Rayyan, L., Wahlby, C. et al. (2021). Genes in human obesity loci are causal obesity genes in C. elegans. PLoS Genetics, 17(9), Atticle e1009736. https://doi.org/10.1371/journal.pgen.1009736 


\section{AUTHOR INFORMATION}

Alexander Y. Prosekov, Doctor of Technical Sciences, Professor, Corresponding Member Russian Academy of Sciences, Rector, Kemerovo State University. 6, Krasnaya str., 650000, Kemerovo, Russia. Tel.: +7-923-502-00-22, E-mail: aprosekov@rambler.ru ORCID: https://orcid.org/0000-0002-5630-3196

Anna D. Vesnina, Postgraduate student, Junior Researcher, Laboratory of Natural Nutraceuticals Biotesting, Research Department, Kemerovo State University. 6, Krasnaya str., 650000, Kemerovo, Russia. Tel.: +7-905-910-26-56, E-mail: koledockop1@mail.ru ORCID: https://orcid.org/0000-0002-4552-7418

* corresponding author

Oksana V. Kozlova, Doctor of Technical Sciences, Docent, Director of the Institute, Kemerovo State University. 6, Krasnaya str., 650000, Kemerovo, Russia. Tel.: +7-3842-39-09-79, E-mail:ms.okvk@mail.ru

ORCID: https://orcid.org/0000-0002-2960-0216

All authors bear responsibility for the work and presented data.

All authors made an equal contribution to the work.

The authors were equally involved in writing the manuscript and bear the equal responsibility for plagiarism.

The authors declare no conflict of interest. 